\title{
Molecular dynamics simulation of effects of nanoparticles on frictional heating and tribological properties at various temperatures
}

\author{
Chengzhi HU, Jizu LV*, Minli BAI, Xiaoliang ZHANG, Dawei TANG \\ Dalian 116024, China \\ Received: 03 September 2018 / Revised: 07 December 2018 / Accepted: 29 December 2018 \\ (C) The author(s) 2019.
}

Laboratory of Ocean Energy Utilization of Ministry of Education, School of Energy and Power Engineering, Dalian University of Technology,

\begin{abstract}
The temperature of a friction pair exerts considerable influence on the tribological behavior of a system. In two cases, one with and the other without $\mathrm{Cu}$ (copper) nanoparticles, the temperature increase in friction pairs caused by frictional heating and its tribological properties at various temperatures are studied by using the molecular dynamics approach. The results show that temperature distribution and surface abrasion are significantly improved by the presence of $\mathrm{Cu}$ nanoparticles. This is one of the reasons for the improvements in tribological properties achieved in the presence of nanoparticles. The temperature and range of influence of frictional heating for the model without nanoparticles are significantly increased with the increase in the sliding velocity; however, in the model with nanoparticles, the temperature gradient is confined to the area near the $\mathrm{Cu}$ film. With an increase in the temperature of the friction pair, the improvement in anti-wear properties associated with the presence of $\mathrm{Cu}$ nanoparticles becomes more significant.
\end{abstract}

Keywords: nanoparticles; molecular dynamics; temperature; tribological properties

\section{Introduction}

With the continuing development of nanotechnology, nanoparticles have begun to be routinely added to lubricants as an oil additive. The results of many experiments on the tribological properties of nanolubricants have shown that the frictional characteristics of the base oil can be significantly improved by the addition of nanoparticles [1-15]. Several mechanisms responsible for the improvement of tribological properties with the addition of nanoparticles have been proposed [16-24], such as rolling friction, a third-body material, a surface protective film, and self-repair effects. Some of these can be addressed experimentally. However, as yet, the theoretical study and direct evidence of lubrication mechanisms of nanoparticles are lacking, and the behavior of nanoparticles between rubbing surfaces has not been studied [25].

There are many asperities on friction surfaces. During the friction process, plastic deformation and adhesive wear occur in the contact zone owing to the compressional shearing action between asperities. The resulting frictional heat is transferred from the outer plastic deformation layer to inside the friction pair, which yields a transient temperature field. Very high temperatures can reduce the strength of a boundary film (such as a physical-chemistry adhesion film) on the friction surface. Because of the temperature gradient, the mechanical properties, such as hardness and elastic modulus, of a friction pair significantly change, which affects the stability of friction. A high local temperature and material softening are two important reasons for wear [26]. Therefore, the

* Corresponding author: Jizu LV, E-mail: lvjizu@dlut.edu.cn 
temperature of a friction pair considerably affects the tribological behavior of a system. As such, the influence of nanoparticles on the temperature increase associated with the asperity contact may be another reason for its excellent effect on tribological properties. Although many studies have been conducted on the tribological behavior of nanoparticles [27], the influence of nanoparticles on the temperature of the rubbing surfaces remains unclear. In addition, tribological parts typically work in high temperature conditions. For instance, the operational temperature region of piston rings ranges from $400 \mathrm{~K}$ to $480 \mathrm{~K}$ [28]. There are few published works on the tribological properties of nanoparticles at various temperatures.

The friction contact zone is instantaneous and hard to observe. Lu et al. [29] developed an experimental method to measure the temperatures of both the surfaces and the oil film in an elastohydrodynamic contact. However, it is not clear whether this method is valid for nanofluids. Nanoparticles are so small that their tribological behavior cannot be captured by macroscopic simulation. To address this problem, molecular dynamics (MD) simulation can be used to calculate trajectories of atoms or molecules by solving Newton's equation of motion and thereby reveal the physical essence of material deformation. A number of MD simulations of the micromechanisms of tribology have been conducted [30]. In Ref. [31], the MD simulation results show that addition of $\mathrm{Cu}$ nanoparticles can form a nano-film between friction pairs, which reduces plastic deformation and structural defects. However, the effect of nanoparticles on the frictional heating and tribological properties of a friction pair at various temperatures has not been considered. Lin et al. [32] used the MD method to simulate the temperature field during nanoscale orthogonal cutting. Chagarov et al. [33] performed an MD simulation of the mechanical deformation of amorphous silicon dioxide during chemical-mechanical polishing and determined the temperature evolution during asperity deformation. Zhong et al. [34] used the MD simulation to obtain the maximum local temperature and temperature gradient during severe adhesive wear on a rough aluminum substrate. Chantrenne [35] performed MD simulation to reveal the generation mechanism of frictional heating and found the potential energy to be the source of frictional heating during plastic transformation. Chen et al. [36] studied the heat dissipation process in nanoscale friction using the MD method and found extensive plastic deformation and increased temperature to occur at the interface. Ewen et al. [37] performed non-equilibrium MD simulations to study the friction properties of carbon nanoparticles between iron surfaces. Their results showed that systems with nanoparticles exhibited lower maximum temperatures than that of systems without nanoparticles. The above works have proved that the temperature increase in a friction pair during asperity contact can be accurately simulated by the MD method. In our previous work, we also verified the feasibility and effectiveness of the MD method in investigating the tribological behaviors of nanoparticles [31, 38-40].

In the light of the above, in this study, we utilized the MD method to investigate changes caused by the presence of $\mathrm{Cu}$ nanoparticles in the temperature of the solid contact zone and the surface abrasion of a friction pair. We also considered the effects of nanoparticles on tribological properties at various temperatures. With respect to frictional heating, this work can be distinguished from the previous studies in that we propose a reasonable explanation for why nanoparticles can improve tribological properties.

\section{Simulation details}

\subsection{Simulation model}

Figure 1 shows two simulation models, in which the diameter of the nanoparticles is $40 \AA$. When no nanoparticles are present, the asperity is in direct contact with the lower block. Periodic boundary conditions are imposed in the $x$-direction and $z$-direction. The material of the friction pair is iron (Fe). The lower block and asperity have the same atomic configuration. There are three layers in the lower block, namely, the rigid layer, thermostat layer, and free deformable layer. The temperature of the thermostat layer is fixed at $T_{0}$ by using the Nose-Hoover thermal bath [41]. The upper asperity is slid at velocity $v$ in the $z$-direction, and a normal external compressive load, $P$, is applied to it. The lower block keeps still during the friction process. Many factors can affect the temperature increase in the friction pair, including 


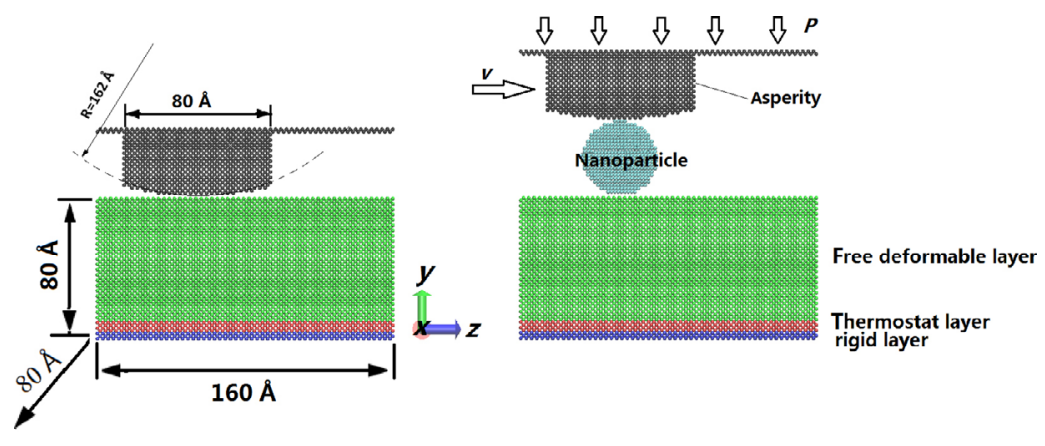

(a)

(b)

Fig. 1 MD simulation models. (a) The model without $\mathrm{Cu}$ nanoparticle, (b) the model with $\mathrm{Cu}$ nanoparticle.

their thermal properties, malleability, and compatibility. To simplify this analysis, the sliding process of a rigid asperity (no deformation and no heat transfer) on the surface of an Fe block will be simulated. Plastic deformation and surface abrasion appear only on the lower Fe block. As such, the temperature increase in the friction pair is determined by the tribological properties of the lower Fe block. Treating the asperity as a rigid body has been adopted in nanoscratching MD simulations [42]. This simplification will not change the friction reduction properties of $\mathrm{Cu}$ nanoparticles. However, all the frictional heat will be transferred through the lower Fe block. Therefore, the temperature distributions in this study differ from the case in which both the blocks are deformed. To simulate the tribological properties at various temperatures, we changed the temperature $\left(T_{0}\right)$ of the thermostat layer.

\subsection{Molecular dynamics}

Interatomic interactions such as $\mathrm{Fe}-\mathrm{Fe}, \mathrm{Cu}-\mathrm{Cu}$, and $\mathrm{Fe}-\mathrm{Cu}$ are all described by the embedded atom method (EAM) potential chosen by Zhong [34], Chen [36], and Ewen [37] to study the temperature increase in the metal friction pair interface:

$$
U=\sum_{i} F_{i}\left(\sum_{j \neq i} \rho_{i}\left(r_{i j}\right)\right)+\frac{1}{2} \sum_{j \neq i} \phi_{i j}\left(r_{i j}\right)
$$

The embedding energy $F_{i}$ is a function of the atomic electron density $\rho . \varphi$ is the pairwise interaction potential. The indices $i$ and $j$ indicate atoms $i$ and $j$, respectively. The EAM potential parameters developed by Bonny et al. [43] are incorporated in the study. Because the parameter set of this potential contains many variables, the same are not given here. The EAM potential documents used in this work can be obtained from Ref. [44].

\subsection{Simulation details}

All the simulations in this work are performed with the classical open source LAMMPS code [45]. Each simulation consists of three steps: initialization, compression, and shear. In initialization, the canonical ensemble (NVT) is chosen for the simulation systems. After 200 ps, an equilibrium state is obtained. Then, a uniformly distributed load, $P$, is gradually imposed on the upper asperity. Later, the NVT ensemble used for the free deformable layers is instead by the micro-canonical ensemble (NVE). Finally, the upper asperity is moved with velocity $v$ on the $z$-direction. The Velocity-Verlet algorithm [46] is used for the numerical integration of the atomic motions. A time step of 0.002 ps was chosen for the simulations.

\section{Results and discussion}

In this study, the temperature increase, surface abrasion, and tribology properties of friction pairs at various temperatures were analyzed. Because load and velocity are two important factors influencing the friction state, four different cases were considered: low load and low velocity $(P=500 \mathrm{MPa}, v=10 \mathrm{~m} / \mathrm{s})$, low load and high velocity $(P=500 \mathrm{MPa}, v=30 \mathrm{~m} / \mathrm{s})$, high load and low velocity $(P=1000 \mathrm{MPa}, v=10 \mathrm{~m} / \mathrm{s})$, and high load and high velocity $(P=1000 \mathrm{MPa}, v=30 \mathrm{~m} / \mathrm{s})$. Unless specified, the temperature of the thermostat layer, $T_{0}$, in the lower block was kept at $300 \mathrm{~K}$. 


\subsection{Friction state}

Figure 2 shows the friction states in the low-load and low-velocity ( $P=500 \mathrm{MPa}$ and $v=10 \mathrm{~m} / \mathrm{s})$ case. To highlight the plastic deformation caused by the shear process, selected atoms in the lower block are colored red. For the system without $\mathrm{Cu}$ nanoparticles, the material on the lower block shifted with the sliding of the upper asperity. Thus, adhesion wear, wear scar, and internal deformation developed in the lower block. After adding the $\mathrm{Cu}$ nanoparticles, the upper asperity became separated from the lower block. The $\mathrm{Cu}$ nanoparticles spread out by the effect of the shearing action to form a nanofilm between friction pairs. The $\mathrm{Cu}$ film facilitated the shearing action between the friction pair; therefore, little deformation occurred in the lower block. This phenomenon is consistent with that in a previous study [31]. The friction processes in the other three cases were similar and are not reported here.

Figure 3 shows the wear states of the model without nanoparticles for the four cases, in which

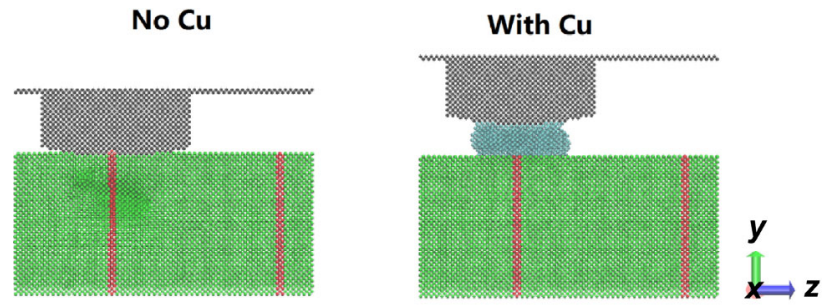

(a) Sliding distance: $0 \AA$
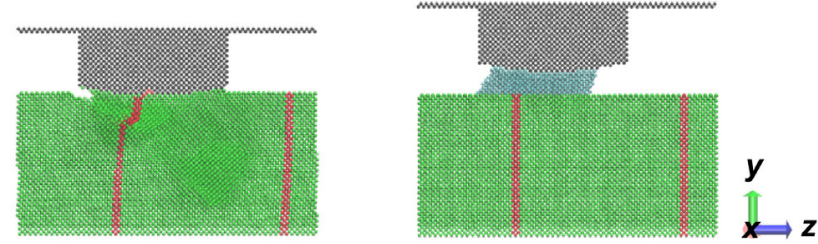

(b) Sliding distance: $18.8 \AA$
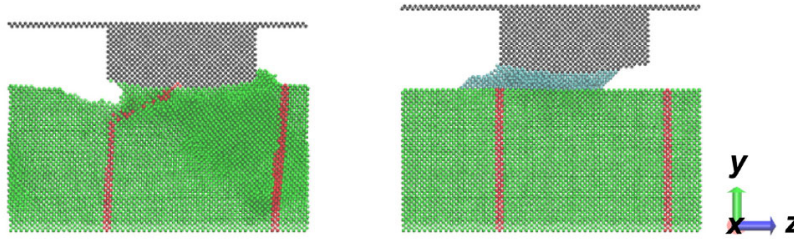

(c) Sliding distance: $38 \AA$

Fig. 2 Still images of friction state after sliding. To visually view the plastic deformation caused by the shear process, selected atoms in the lower block have been colored in red. $P=500 \mathrm{MPa}$, $v=10 \mathrm{~m} / \mathrm{s}$.

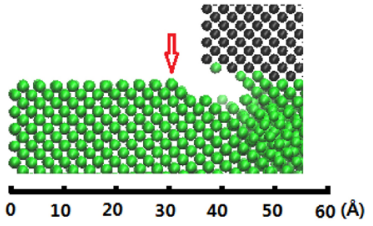

(a) $P=500 \mathrm{MPa} v=10 \mathrm{~m} / \mathrm{s}$

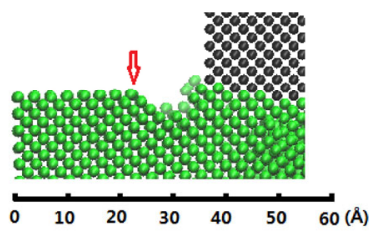

(c) $P=1000 \mathrm{MPa} \quad V=10 \mathrm{~m} / \mathrm{s}$

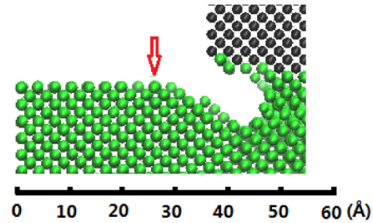

(b) $P=500 \mathrm{MPa} v=30 \mathrm{~m} / \mathrm{s}$

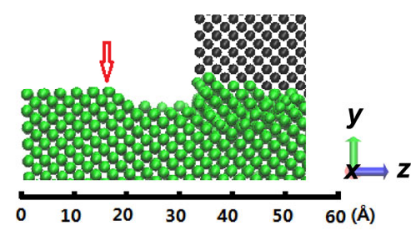

(d) $P=1000 \mathrm{MPa} v=30 \mathrm{~m} / \mathrm{s}$
Fig. 3 Surface abrasion of the lower block at the sliding distance of $18.8 \AA$. Locations pointed to by arrows were the starting positions of wear.

one can see that adhesive wear occurred on friction surfaces. The locations indicated by the arrows show the starting positions of wear. It can be found that the closer the starting positions to the left boundary of the lower block, the larger the wear scar widths. The coordinates of the wear scars along the $z$-axis for the four cases were $30 \AA(P=500 \mathrm{MPa}, v=10 \mathrm{~m} / \mathrm{s}), 26 \AA(P=$ $500 \mathrm{MPa}, v=30 \mathrm{~m} / \mathrm{s}), 22 \AA(P=000 \mathrm{MPa}, v=10 \mathrm{~m} / \mathrm{s})$, and $16 \AA(P=1000 \mathrm{MPa}, v=30 \mathrm{~m} / \mathrm{s})$, respectively. As shown in Fig. 3, the wear scar width increased with an increase in the load and sliding velocity. The reason lies in that both the strength of the interatomic bonds and the contact area between the friction pair increased with an increase in the load. More atoms on the lower block were shifted with the sliding of the asperity, which resulted in a wider wear scar. Therefore, the wear scar in the $P=1000 \mathrm{MPa}$ and $v=30 \mathrm{~m} / \mathrm{s}$ case was the widest. For the model with $\mathrm{Cu}$ nanoparticles, no wear occurred on the friction surface owing to the presence of the $\mathrm{Cu}$ film (as shown in Fig. 2). Even at a high velocity and high load, the friction surface remained well protected by the $\mathrm{Cu}$ nanoparticles. These results indicate that $\mathrm{Cu}$ nanoparticles impart better anti-wear properties under high-speed and heavy-load conditions.

\subsection{Temperature increase}

The increase in temperature caused by frictional heating can be computed from the kinetic energy of atoms. However, if the atomic temperature is used directly, only some discrete points can be obtained. In 
this study, every atom is treated as one central atom. To obtain the temperature distribution, the average temperature of atoms within $6 \AA$ of the central atom is assigned to the central atom. Figures $4-7$ show the respective temperature distributions of the four cases. For the model without nanoparticles, the asperity made contact with the lower block by the application of a normal load. Plastic deformation was produced by mechanical force. Frictional power was transformed into frictional heating, which then diffused into the interior of the lower block. Consequently, the temperature increased. The temperature of the solid contact zone reached $450 \mathrm{~K}$, because this is where severe plastic deformations occurred. For the model with $\mathrm{Cu}$ nanoparticles, the $\mathrm{Cu}$ film facilitated the shearing action in the high-temperature zone. Fortunately, the influence of frictional heating is very limited. A temperature gradient occurred only in the area connecting the lower block and the $\mathrm{Cu}$ film. Upon addition of the $\mathrm{Cu}$ nanoparticles, the temperature increase in the friction pair was significantly improved, which means that frictional heating was drastically reduced. Accordingly, the thermal stress and fluctuation of the mechanical properties of the
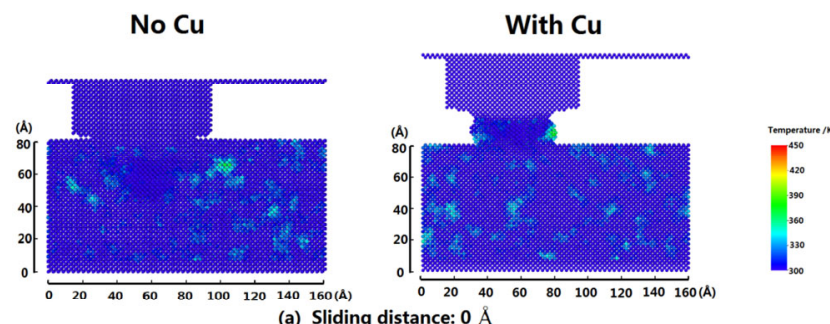

(a) Sliding distance: $0 \AA$
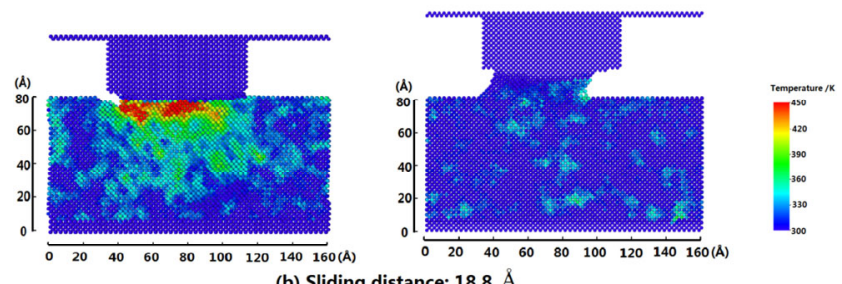

(b) Sliding distance: $18.8 \AA$
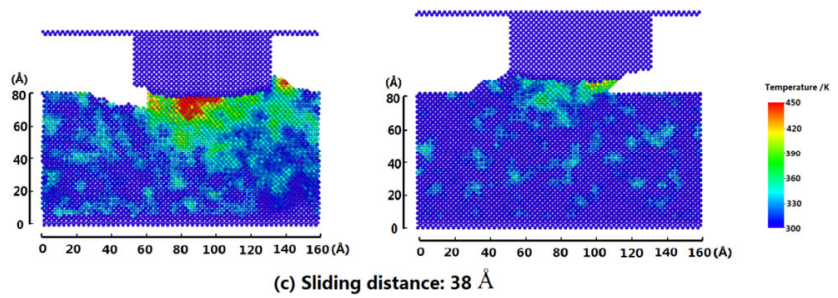

Fig. 4 Temperature distribution of friction pair at different sliding distances. $P=500 \mathrm{MPa}, v=10 \mathrm{~m} / \mathrm{s}$.

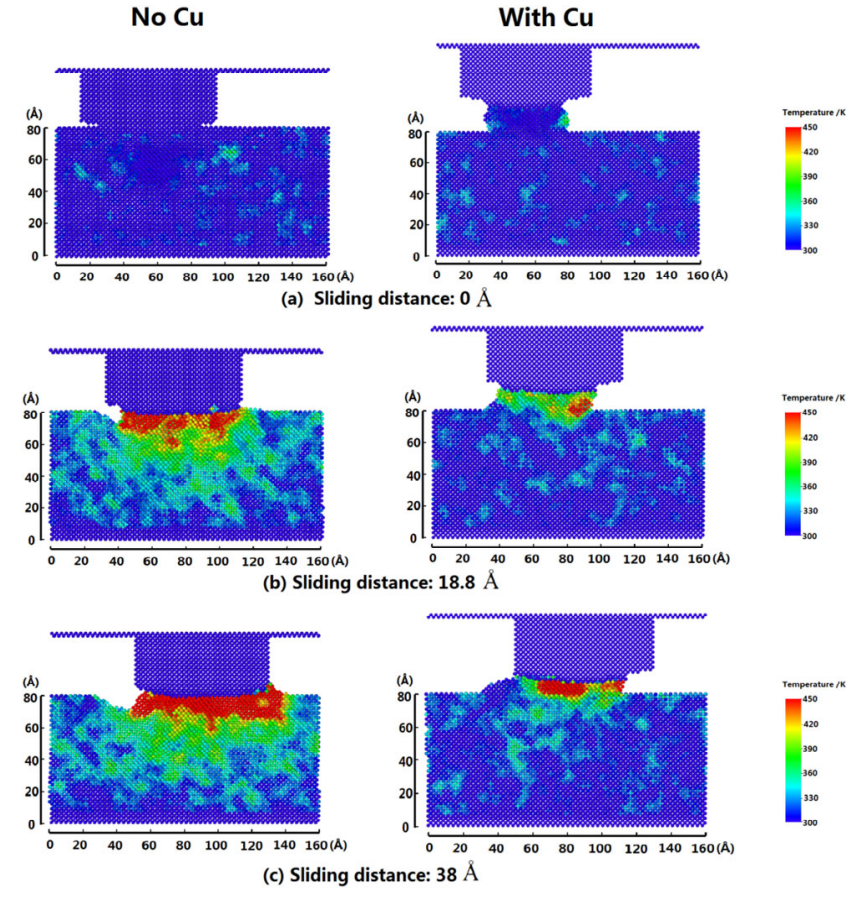

Fig. 5 Temperature distribution of friction pair at different sliding distances. $P=500 \mathrm{MPa}, v=30 \mathrm{~m} / \mathrm{s}$.
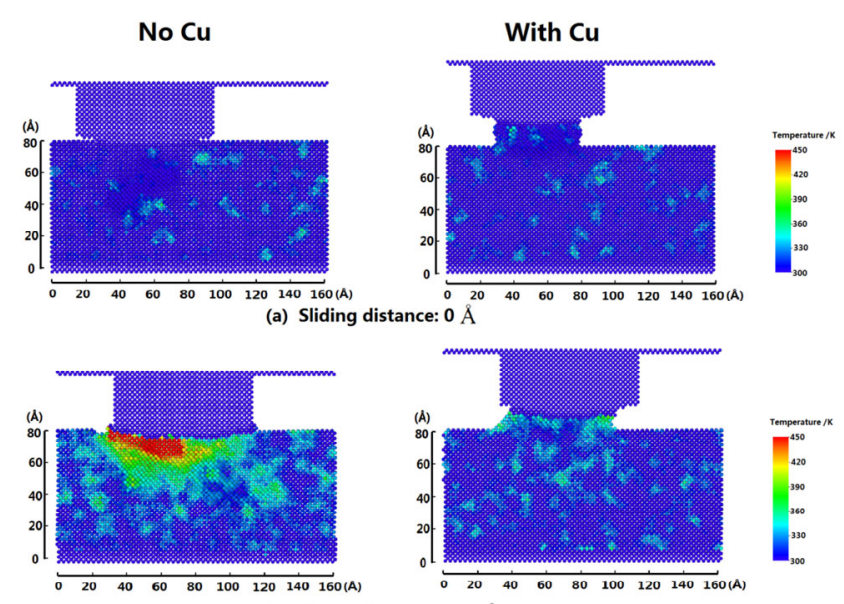

(b) Sliding distance: $18.8 \AA$

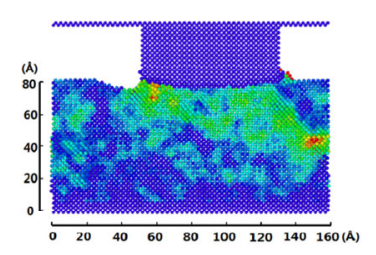

(c) Sliding distance: $38 \AA$

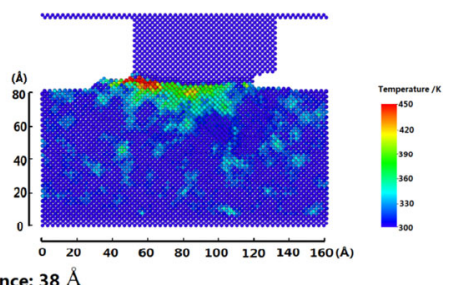

Fig. 6 Temperature distribution of friction pair at different sliding distances. $P=1000 \mathrm{MPa}, v=10 \mathrm{~m} / \mathrm{s}$.

friction pair caused by frictional heating was weakened. Thus, it can be concluded that the $\mathrm{Cu}$ film not only reduces friction and improves anti-wear properties, but also effectively reduces the local temperature 

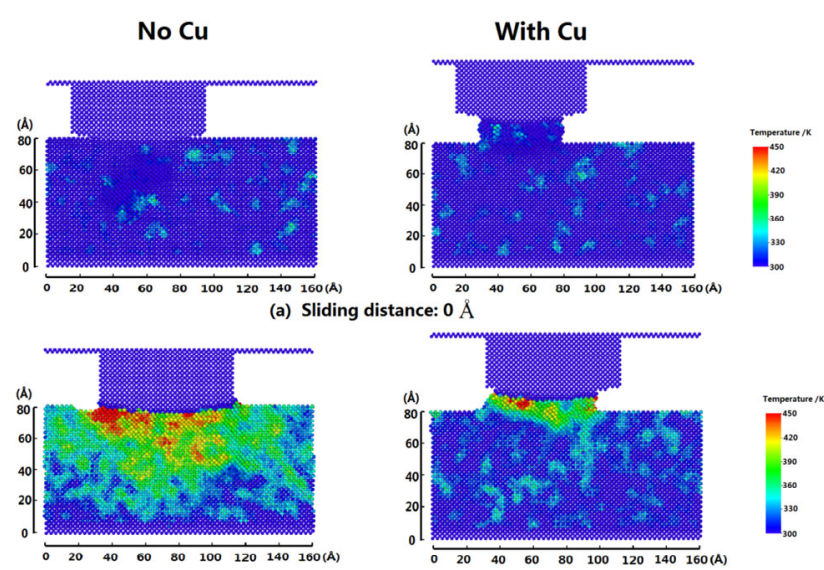

(b) Sliding distance: $18.8 \AA$

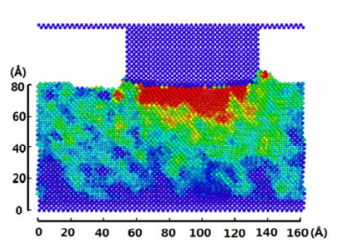

(c) Sliding distance: $38 \AA$

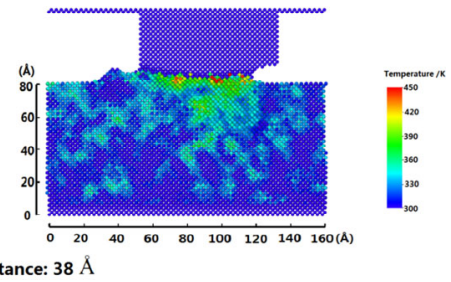

Fig. 7 Temperature distribution of friction pair at different sliding distances. $P=1000 \mathrm{MPa}, v=30 \mathrm{~m} / \mathrm{s}$.

increase at the friction-pair interface, which is beneficial to the mechanical stability of the friction pair.

To obtain a better quantitative law from simulation results, the lower block is divided into several layers perpendicular to the $y$-axis, and the average temperature of each layer during the sliding process is obtained. Figure 8 shows the temperature profiles along the $y$-axis, in which it can be seen that, for both models, the temperature caused by frictional heating increases with an increase in the load and sliding velocity. After adding the $\mathrm{Cu}$ nanoparticles, the temperature of the lower block was significantly reduced. For the model without nanoparticles, the range of influence of frictional heating extends allover the block. Because of the improvement in the tribological behaviors provided by $\mathrm{Cu}$ nanoparticles, only the area from $75 \AA$ to $80 \AA$ along the $y$-axis was influenced by frictional heating. When there were no nanoparticles, the temperature, area of the hightemperature zone, and range of influence of frictional heating were obviously increased as the velocity increased from $10 \mathrm{~m} / \mathrm{s}$ to $30 \mathrm{~m} / \mathrm{s}$. For the model with $\mathrm{Cu}$ nanoparticles, although the range of influence of frictional heating expanded with an increase in the velocity, the temperature gradient was limited to the

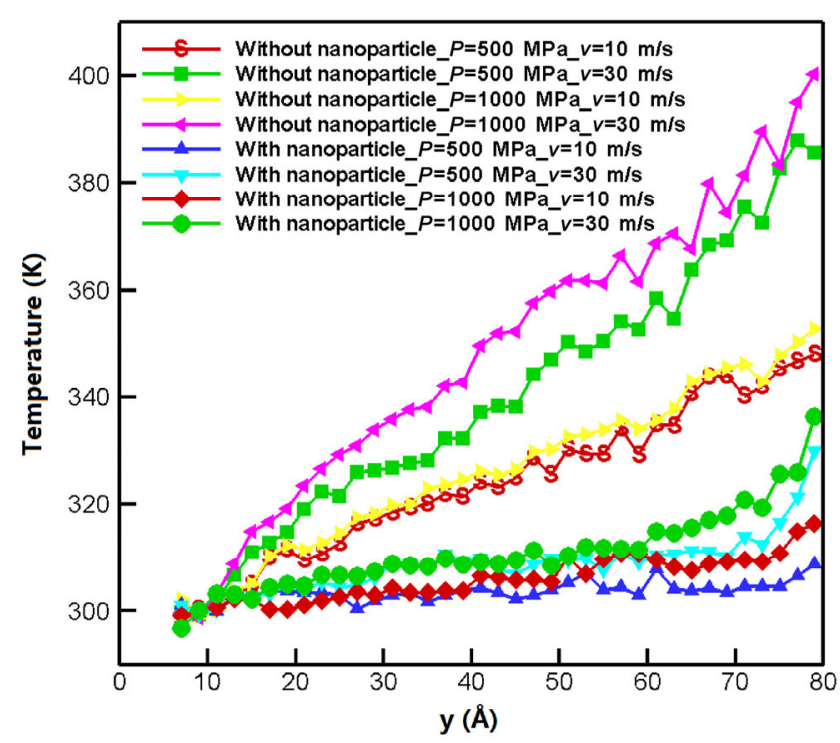

Fig. 8 Temperature profiles of lower block along the $y$-axis.

area near the $\mathrm{Cu}$ film. By comparing Fig. 4 and Fig. 5 or Fig. 6 and Fig. 7, the same results can be observed. These findings show a more significant improvement in the temperature increase at a high sliding velocity owing to the presence of $\mathrm{Cu}$ nanoparticles.

For a better comparative analysis, the frictional heat and average temperature $\left(T_{\text {ave }}\right)$ of the lower Fe block are summarized in Table 1 . To show the size of the local high-temperature zone, the ratio $(\phi)$ of the high temperature zone $(>400 \mathrm{~K})$ to the bulk volume of the lower Fe block is computed, which is also shown in Table 1. It can be found that frictional heat is reduced by $62 \%-80 \%$ with the addition of $\mathrm{Cu}$ nanoparticles. Because of this, the $T_{\text {ave }}$ values of the model with $\mathrm{Cu}$ nanoparticles in the four cases decrease by $21 \mathrm{~K}, 32 \mathrm{~K}, 23 \mathrm{~K}$, and $38 \mathrm{~K}$, respectively. For the model without $\mathrm{Cu}$ nanoparticles, the ratio of the high temperature zone increased from $9.4 \%$ to $26 \%$ with an increase in the load and velocity. However, when the $\mathrm{Cu}$ nanoparticles are added, the volume fraction falls to $0.1 \%-1.8 \%$.

\subsection{Effect of system temperature}

The thermophysical and mechanical properties of tribological parts change with the temperature under the working conditions, and the tribology properties also vary. In this section, we study whether $\mathrm{Cu}$ nanoparticles can effectively improve friction properties at high temperatures. Figure 9 shows the surface abrasion 
Table 1 Frictional heat, average temperature $\left(T_{\text {ave }}\right)$ of the lower Fe block, and ratio $(\varphi)$ of high temperature zone $(>400 \mathrm{~K})$ to the bulk volume of the lower Fe block at the sliding distance of $38 \AA$.

\begin{tabular}{|c|c|c|c|c|c|}
\hline Model & Parameters & $\begin{array}{c}P=500 \mathrm{MPa} \\
v=10 \mathrm{~m} / \mathrm{s}\end{array}$ & $\begin{array}{c}P=500 \mathrm{MPa} \\
v=30 \mathrm{~m} / \mathrm{s}\end{array}$ & $\begin{array}{c}P=1000 \mathrm{MPa} \\
v=10 \mathrm{~m} / \mathrm{s}\end{array}$ & $\begin{array}{c}P=1000 \mathrm{MP} \\
v=30 \mathrm{~m} / \mathrm{s}\end{array}$ \\
\hline \multirow{3}{*}{ Without $\mathrm{Cu}$} & Frictional heat $(\mathrm{eV})$ & 131 & 351 & 141 & 388 \\
\hline & $T_{\text {ave }}(\mathrm{K})$ & 324 & 340 & 328 & 348 \\
\hline & $\varphi(\%)$ & 9.4 & 16 & 9.8 & 26 \\
\hline \multirow{3}{*}{ With $\mathrm{Cu}$} & Frictional heat $(\mathrm{eV})$ & 28 & 107 & 53 & 137 \\
\hline & $T_{\text {ave }}(\mathrm{K})$ & 303 & 308 & 305 & 310 \\
\hline & $\varphi(\%)$ & 0.1 & 0.98 & 0.25 & 1.8 \\
\hline
\end{tabular}

No $\mathrm{Cu}$

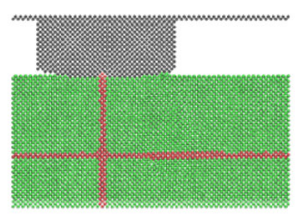

(a) Sliding distance: $0 \AA$

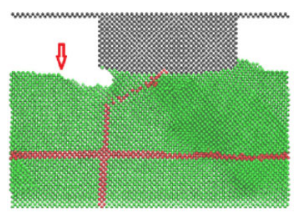

(b) $T_{0}=300 \mathrm{~K}$ Sliding distance: $38 \AA$
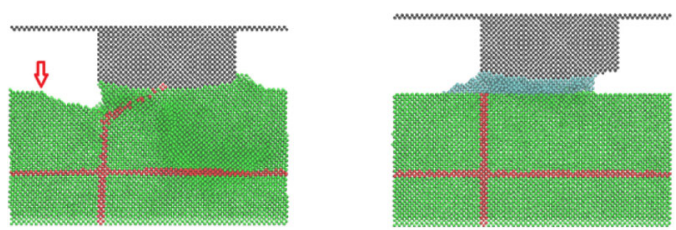

(c) $T_{0}=400 \mathrm{~K}$ Sliding distance: $38 \AA$
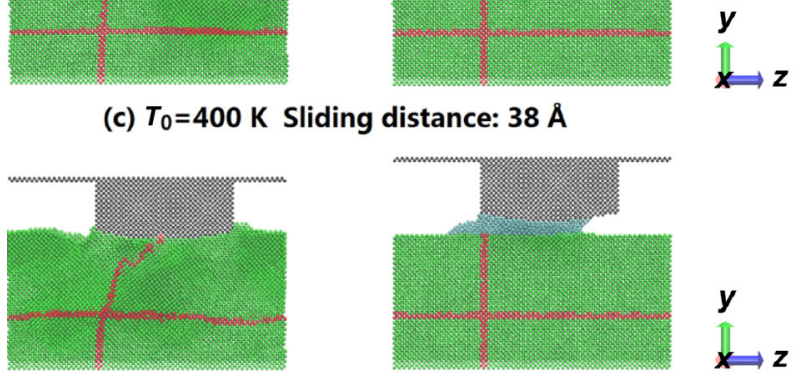

(d) $T_{0}=480 \mathrm{~K}$ Sliding distance: $38 \AA$

Fig. 9 Surface abrasion and shear deformation at different temperatures. The color rule for atoms is the same as that in Fig. 2. $P=500 \mathrm{MPa}, \nu=10 \mathrm{~m} / \mathrm{s}$.

and shear deformation at different temperatures. For the model without $\mathrm{Cu}$ nanoparticles, when temperature $T_{0}$ was increased from $300 \mathrm{~K}$ to $400 \mathrm{~K}$, the width of the wear scar increased. When the temperature was increased to $480 \mathrm{~K}$, softening of the material caused mass deformation within the lower block. These results show that when there are no nanoparticles, the wear state becomes more serious with an increase in the temperature of the friction pair. For the model with $\mathrm{Cu}$ nanoparticles, $\mathrm{Cu}$ films formed on the friction surface at all three temperatures. Even in high-temperature conditions, there was no apparent deformation in the friction pair, with the degree of wear at the high temperature close to that at the low temperature. This indicates that $\mathrm{Cu}$ nanoparticles still exhibit good anti-wear performance at high temperatures. Therefore, it can be concluded that the improved effect of $\mathrm{Cu}$ nanoparticles on tribology properties is more significant at higher temperatures.

Figure 10 shows the distributions of structural
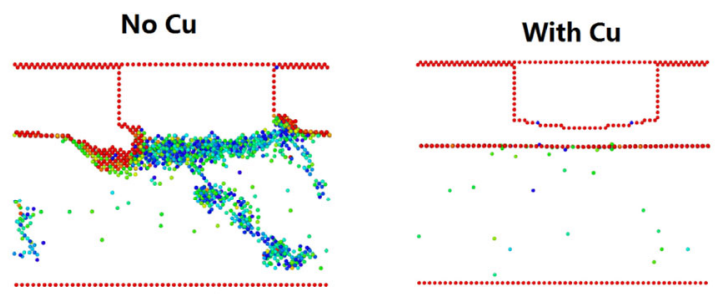

(a) $T_{0}=300 \mathrm{~K}$
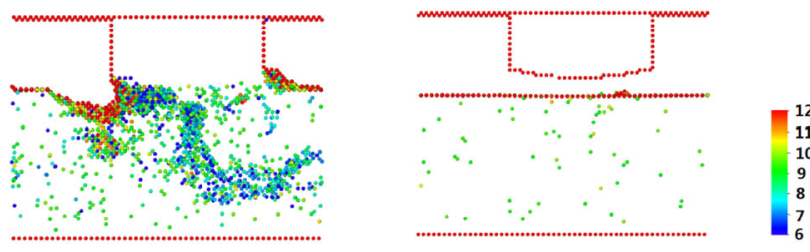

(b) $T_{0}=400 \mathrm{~K}$
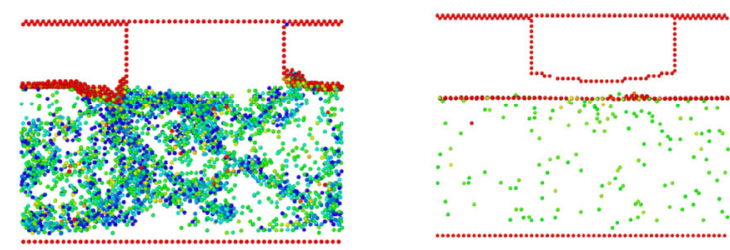

(c) $T_{0}=480 \mathrm{~K}$

Fig. 10 Structural defects at different temperatures. $P=500 \mathrm{MPa}$, $v=10 \mathrm{~m} / \mathrm{s}$. Only atoms with centrosymmetry parameter larger than 6 are shown. $\mathrm{Cu}$ atoms are not shown. 
defects at various temperatures, in which atoms are colored based on their centro-symmetry parameter [31]. It can be seen that the number of structural defects was significantly reduced by adding the $\mathrm{Cu}$ nanoparticles. With an increased temperature, the number of structural defects in the model without nanoparticles increased significantly; whereas, in the model with $\mathrm{Cu}$ nanoparticles, the number of structural defects increased only slightly because of the presence of the $\mathrm{Cu}$ film. These findings also indicate that the improvement in friction characteristics at high temperatures caused by the presence of nanoparticles was more significant than that at low temperatures, which is consistent with the results shown in Fig. 9.

\section{Conclusion}

In this study, the MD method was used to investigate the changes in the temperature of a friction surface caused by frictional heating under two conditions: with $\mathrm{Cu}$ nanoparticles and without $\mathrm{Cu}$ nanoparticles. Compared with the model without nanoparticles, the temperature increase caused by frictional heating and surface abrasion in the model with $\mathrm{Cu}$ nanoparticles improved significantly. With an increased sliding velocity, the temperature and range of influence of frictional heating in the model without nanoparticles were significantly increased. In contrast, in the model with $\mathrm{Cu}$ nanoparticles, as the sliding velocity increased, the temperature gradient was confined to the area near the $\mathrm{Cu}$ film. The significant effect of $\mathrm{Cu}$ nanoparticles in improving the temperature distribution of a friction pair in asperity contact is beneficial to the mechanical stability of rubbing surfaces.

The tribological effects of nanoparticles at various temperatures were also investigated. In the model without nanoparticles, the surface abrasion, plastic deformation, and defect structures became more serious with an increase in the temperature $T_{0}$ of the friction pair. In the model with $\mathrm{Cu}$ nanoparticles, the degree of wear at high temperatures was close to that at low temperatures, which indicates that $\mathrm{Cu}$ nanoparticles perform extremely well in improving tribological properties even at high temperatures.

\section{Acknowledgements}

This work is supported by National Natural Science Foundation of China (Grant No. 51806028, 51876027, 51476019, and 51376002) and the Fundamental Research Funds for the Central Universities (DUT17RC(3)043 and DUT 17JC23).

Open Access This article is licensed under a Creative Commons Attribution 4.0 International License, which permits use, sharing, adaptation, distribution and reproduction in any medium or format, as long as you give appropriate credit to the original author(s) and the source, provide a link to the Creative Commons licence, and indicate if changes were made.

The images or other third party material in this article are included in the article's Creative Commons licence, unless indicated otherwise in a credit line to the material. If material is not included in the article's Creative Commons licence and your intended use is not permitted by statutory regulation or exceeds the permitted use, you will need to obtain permission directly from the copyright holder.

To view a copy of this licence, visit http://creativecommons.org/licenses/by/4.0/.

\section{References}

[1] Ye W Y, Cheng T F, Ye Q, Guo X Y, Zhang Z J, Dang H X. Preparation and tribological properties of tetrafluorobenzoic acid-modified $\mathrm{TiO}_{2}$ nanoparticles as lubricant additives. Mater Sci Eng A 359(1-2): 82-85 (2003)

[2] Peng D X, Kang Y, Hwang R M, Shyr S S, Chang Y P. Tribological properties of diamond and $\mathrm{SiO}_{2}$ nanoparticles added in paraffin. Tribol Int 42(6): 911-917 (2009)

[3] Chou R, Battez A H, Cabello J J, Viesca J L, Osorio A, Sagastume A. Tribological behavior of polyalphaolefin with the addition of nickel nanoparticles. Tribol Int 43(12): 2327-2332 (2010)

[4] Hernández Battez A, Viesca J L, González R, Blanco D, Asedegbega E, Osorio A. Friction reduction properties of a $\mathrm{CuO}$ nanolubricant used as lubricant for a NiCrBSi coating. Wear 268(1-2): 325-328 (2010)

[5] Ma S Y, Zheng S H, Cao D X, Guo H N. Anti-wear and friction performance of $\mathrm{ZrO}_{2}$ nanoparticles as lubricant additive. Particuology 8(5): 468-472 (2010)

[6] Ji X B, Chen Y X, Zhao G Q, Wang X B, Liu W M. Tribological properties of $\mathrm{CaCO}_{3}$ nanoparticles as an additive 
in lithium grease. Tribol Lett 41(1): 113-119 (2011)

[7] Nan F, Xu Y, Xu B S, Gao F, Wu Y X, Li Z G. Tribological behaviors and wear mechanisms of ultrafine magnesium aluminum silicate powders as lubricant additive. Tribol Int 81: 199-208 (2015)

[8] Padgurskas J, Rukuiza R, Prosyčevas I, Kreivaitis R. Tribological properties of lubricant additives of $\mathrm{Fe}, \mathrm{Cu}$ and Co nanoparticles. Tribol Int 60: 224-232 (2013)

[9] Elomaa O, Oksanen J, Hakala T J, Shenderova O, Koskinen J. A comparison of tribological properties of evenly distributed and agglomerated diamond nanoparticles in lubricated highload steel-steel contact. Tribol Int 71: 62-68 (2014)

[10] Alves S M, Mello V S, Faria E A, Camargo A P P. Nanolubricants developed from tiny $\mathrm{CuO}$ nanoparticles. Tribol Int 100: 263-271 (2016)

[11] Song X Y, Zheng S H, Zhang J, Li W, Chen Q, Cao B Q. Synthesis of monodispersed $\mathrm{ZnAl}_{2} \mathrm{O}_{4}$ nanoparticles and their tribology properties as lubricant additives. Mater Res Bull 47(12): 4305- 4310 (2012)

[12] Viesca J L, Hernández Battez A, González R, Chou R, Cabello J J. Antiwear properties of carbon-coated copper nanoparticles used as an additive to a polyalphaolefin. Tribol Int 44(7-8): 829-833 (2011)

[13] Pan Q H, Zhang X F. Synthesis and tribological behavior of oil-soluble $\mathrm{Cu}$ nanoparticles as additive in SF15W/40 lubricating oil. Rare Met Mater Eng 39(10): 1711-1714 (2010)

[14] Zhang M, Wang X B, Liu W M, Fu X S. Performance and anti-wear mechanism of $\mathrm{Cu}$ nanoparticles as lubricating oil additives. Ind Lubr Tribol 61(6): 311-318 (2009)

[15] Zhang C L, Zhang S M, Song S Y, Yang G B, Yu L G, Wu Z S, Li X H, Zhang P Y. Preparation and tribological properties of surface-capped copper nanoparticle as a waterbased lubricant additive. Tribol Lett 54(1): 25-33 (2014)

[16] Choi Y, Lee C, Hwang Y, Park M, Lee J, Choi C, Jung M. Tribological behavior of copper nanoparticles as additives in oil. Curr Appl Phys 9(S2): e124-e127 (2009)

[17] Hernández Battez A, González R, Viesca J L, Fernández J E, Díaz Fernández J M, Machado A, Chou R, Riba J. CuO, $\mathrm{ZrO}_{2}$ and $\mathrm{ZnO}$ nanoparticles as antiwear additive in oil lubricants. Wear 265(3-4): 422-428 (2008)

[18] Gao Y J, Chen G X, Oli Y, Zhang Z J, Xue Q J. Study on tribological properties of oleic acid-modified $\mathrm{TiO}_{2}$ nanoparticle in water. Wear 252(5-6): 454-458 (2002)

[19] Xu T, Zhao J Z, Xu K. The ball-bearing effect of diamond nanoparticles as an oil additive. J Phys D: Appl Phys 29(11): 2932-2937 (1996)

[20] Wu Y Y, Tsui W C, Liu T C. Experimental analysis of tribological properties of lubricating oils with nanoparticle additives. Wear 262(7-8): 819-825 (2007)
[21] Jiao D, Zheng S H, Wang Y Z, Guan R F, Cao B Q. The tribology properties of alumina/silica composite nanoparticles as lubricant additives. Appl Surf Sci 257(13): 5720-5725 (2011)

[22] Lee J, Cho S, Hwang Y, Lee C, Kim S H. Enhancement of lubrication properties of nano-oil by controlling the amount of fullerene nanoparticle additives. Tribol Lett 28(2): 203-208 (2007)

[23] Kogovšek J, Remškar M, Mrzel A, Kalin M. Influence of surface roughness and running-in on the lubrication of steel surfaces with oil containing $\mathrm{MoS}_{2}$ nanotubes in all lubrication regimes. Tribol Int 61: 40-47 (2013)

[24] Zhang B S, Xu B S, Xu Y, Gao F, Shi P J, Wu Y X. CU nanoparticles effect on the tribological properties of hydrosilicate powders as lubricant additive for steel-steel contacts. Tribol Int 44(7-8): 878-886 (2011)

[25] Spikes H. Friction modifier additives. Tribol Lett 60(1): 5 (2015)

[26] Archard J F. The temperature of rubbing surfaces. Wear 2(6): 438-455 (1959)

[27] Dai W, Kheireddin B, Gao H, Liang H. Roles of nanoparticles in oil lubrication. Tribol Int 102: 88-98 (2016)

[28] Chang H S, Wayte R, Spikes H A. Measurement of piston ring and land temperatures in a firing engine using infrared. Tribol Trans 36(1): 104-112 (1993)

[29] Lu J, Reddyhoff T, Dini D. 3D Measurements of lubricant and surface temperatures within an elastohydrodynamic contact. Tribol Lett 66: 7 (2018)

[30] Ewen J P, Heyes D M, Dini D. Advances in nonequilibrium molecular dynamics simulations of lubricants and additives. Friction 6(4): 349-386 (2018)

[31] Hu C Z, Bai M L, Lv J Z, Liu H, Li X J. Molecular dynamics investigation of the effect of copper nanoparticle on the solid contact between friction surfaces. Appl Surf Sci 321: 302-309 (2014)

[32] Lin Z C, Lin M H, Hsu Y C. Simulation of temperature field during nanoscale orthogonal cutting of single-crystal silicon by molecular statics method. Comput Mater Sci $\mathbf{8 1}$ : 58-67 (2014)

[33] Chagarov E, Adams J B. Molecular dynamics simulations of mechanical deformation of amorphous silicon dioxide during chemical-mechanical polishing. J Appl Phys 94(6): 3853-3861 (2003)

[34] Zhong J, Shakiba R, Adams J B. Molecular dynamics simulation of severe adhesive wear on a rough aluminum substrate. J Phys D: Appl Phys 46(5): 055307 (2013)

[35] Chantrenne P. Multiscale simulations: Application to the heat transfer simulation of sliding solids. Int J Mater Form 1(1): 31-37 (2008) 
[36] Chen K, Wang L B, Chen Y, Wang Q W. Molecular dynamics simulation of microstructure evolution and heat dissipation of nanoscale friction. Int J Heat Mass Transfer 109: 293-301 (2017)

[37] Ewen J P, Gattinoni C, Thakkar F M, Morgan N, Spikes H A, Dini D. Nonequilibrium molecular dynamics investigation of the reduction in friction and wear by carbon nanoparticles between iron surfaces. Tribol Lett 63(3): 38 (2016)

[38] Hu C Z, Bai M L, Lv J Z, Kou Z H, Li X J. Molecular dynamics simulation on the tribology properties of two hard nanoparticles (diamond and silicon dioxide) confined by two iron blocks. Tribol Int 90: 297-305 (2015)

[39] Hu C Z, Bai M L, Lv J Z, Li X J. Molecular dynamics simulation of mechanism of nanoparticle in improving load-carrying capacity of lubricant film. Comput Mater Sci 109: 97-103 (2015)

[40] Hu C Z, Bai M L, Lv J Z, Wang P, Li X J. Molecular dynamics simulation on the friction properties of nanofluids confined by idealized surfaces. Tribol Int 78: 152-159 (2014)

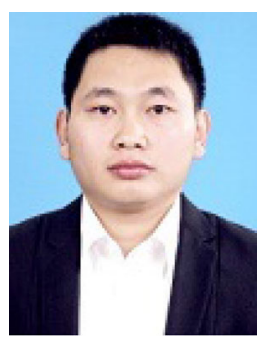

Chengzhi HU. He is an assistant professor in Laboratory of Ocean Energy Utilization of Ministry of Education at Dalian University of Technology. He received his Ph.D

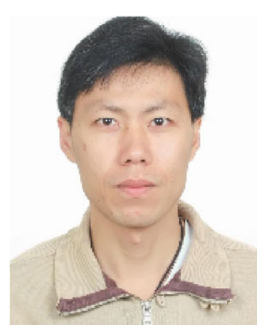

Jizu LV. His current position is an associate professor in Laboratory of Ocean Energy Utilization of Ministry of Education at Dalian University of Technology. He received his Ph.D degree in power

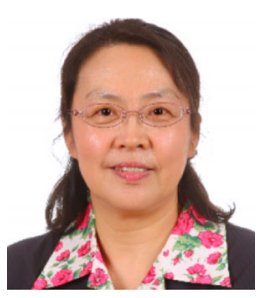

Minli BAI. Her current position is a professor in Laboratory of Ocean Energy Utilization of Ministry of Education at Dalian University of Technology. She received her Ph.D
[41] Hoover W G. Canonical dynamics: Equilibrium phase-space distributions. Phys Rev A 31(3): 1695-1697 (1985)

[42] Gao Y, Brodyanski A, Kopnarski M, Urbassek H M. Nanoscratching of iron: A molecular dynamics study of the influence of surface orientation and scratching direction. Comput Mater Sci 103: 77-89 (2015).

[43] Bonny G, Pasianot R C, Castin N, Malerba L. Ternary $\mathrm{Fe}-\mathrm{Cu}-\mathrm{Ni}$ many-body potential to model reactor pressure vessel steels: First validation by simulated thermal annealing. Philos Mag 89(34-36): 3531-3546 (2009)

[44] Website. https://www.ctcms.nist.gov/potentials/system/Fe/

[45] Plimpton S. Fast parallel algorithms for short-range molecular dynamics. J Comput Phys 117(1): 1-19 (1995)

[46] Swope W C, Andersen H C, Berens P H, Wilson K R. A computer simulation method for the calculation of equilibrium constants for the formation of physical clusters of molecules: Application to small water clusters. $J$ ChemPhys 76(1): 637-649 (1982)

degree in engineering thermophysics from Dalian University of Technology, China, in 2016. His research involves the friction properties of micro-nanostructure surface and nano-lubricants.

engineering and engineering thermophysics from Dalian University of Technology, China, in 2009. His research involves the heat transfer enhancement of nanofluids inside the piston cooling gallery of internal combustion engines.

degree in power engineering and engineering thermophysics from Dalian University of Technology, China, in 1996. Her research involves the coupled mechanism of heat transfer, lubrication and friction for piston set-liner of internal combustion engine. 


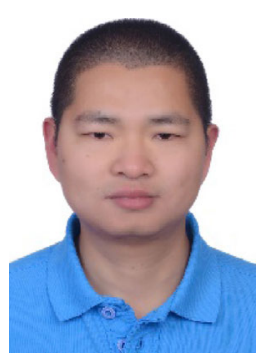

Xiaoliang ZHANG. He has been an associate professor in School of Energy and Power Engineering at Dalian University of Technology, China since 2016. He received his Ph.D degree in engineering thermophysics from Chinese Academy of Sciences in 2013. He was a joint Ph.D student in Laboratory of Thermodynamics in

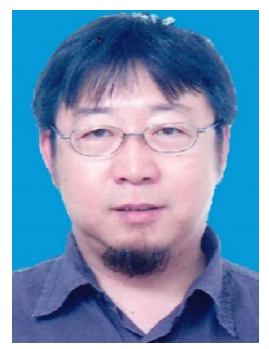

Dawei TANG. He received his Ph.D degree in thermal science from Shizuoka University, Japan, in 1999. He joined the School of Energy and Power Engineering at Dalian University of Technology from 2016. His current position is a professor
Emerging Technologies at ETH Zurich between 2010 and 2011. He was a research engineer in Department of Chemical and Biomolecular Engineering at National University of Singapore between 2012 and 2013. After Ph.D graduation, he worked as a postdoctoral researcher at RWTH Aachen University between 2013 and 2016. His research is mainly focused on molecular dynamics simulations and first-principles calculations of nanoscale thermal transport.

and the dean of School of Energy and Power Engineering. His research areas cover the characterization and evaluation of thermophysical properties of advanced functional materials, advanced thermal management technology, and solar-thermal steam reforming technology. 